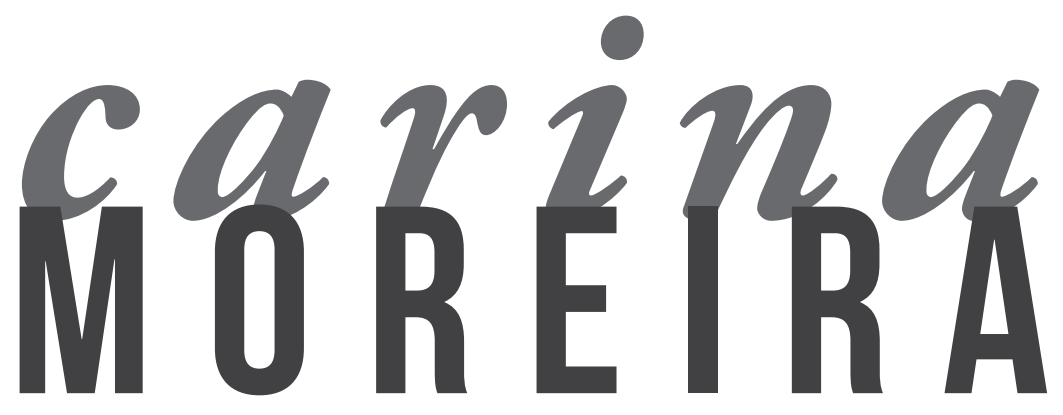

Universidade Federal do Estado do Rio de Janeiro (UniRio)

\title{
BARAFONDA: DIALÉTICA DA TRAGÉDIA COTIDIANA
}

RESUMO $>$ a partir do conceito de Tragédia Moderna de Raymond Williams e através da análise da estrutura da dramaturgia do espetáculo Barafonda, do grupo teatral paulista Companhia São Jorge de Variedades, apresentado no ano de 2012, o presente artigo se propôe apontar os aspectos políticos contidos em suas escolhas formais e temáticas.

PALAVRAS-CHAVE> Tragédia Moderna; Coralidade; Teatro e Política. 


\section{BARAFONDA:}

\section{DIALÉTICA DA TRAGÉDIA}

\section{COTIDIANA}

De forma obliqua e confusa, reconhece-se que a luta por dinheiro substituiu a luta por poder como um motivo humano e um motivo trágico. Raymond Williams

O espetáculo Barafonda, encenado pela Cia São Jorge de Variedades (SP) em 2011, explicita em sua estrutura formal a presença de duas tragédias clássicas ao organizar-se em torno de dois mitos: o mito de Prometeu (com referências diretas à tragédia Prometeu Acorrentado de Ésquilo) e o mito de Dionísio (também com referências à tragédia As Bacantes de Eurípedes). Essa formulaçáo promove um questionamento quanto à herança de ideais como progresso e felicidade, e as suas possíveis íntimas relaçóes contemporâneas. As tragédias formam também a base para experimentaçóes com o coro teatral, desenvolvido no sentido de uma linguagem potencialmente política em sua forma coletiva de expressão, lançando mão de um modo de expressão da memória coletiva. $\mathrm{O}$ coro permeia toda a ação desenvolvida, não apenas em sua função tradicional de pontuar e comentar as açóes, mas como protagonista e antagonista, em açóes coletivizadas.

Neste contexto, o presente artigo propóe, a partir do espetáculo Barafonda, apontar os aspectos políticos contidos nas escolhas formais e temáticas, proposto a partir do conceito de Tragédia Moderna de Raymond Williams (2002). Porém, o que leva a leitura de Barafonda como uma tragédia, imbuída, portanto, da ideia de trágico, vai além dos dois mitos já de início indicados, sem tirar-lhes a devida importância, pois tal esbarra numa questão fundamental para o emprego da dimensão política na obra: tratase da compreensão conceitual de que os acontecimentos cotidianos
1 O presente artigo é fruto da pesquisa de doutoramento "Encenaçáo e Dimensão Política: uma 'Barafonda' na cena contemporânea”, defendida em 2014 no PPGAC-UNIRIO, sob orientação da Profa. Dr. Beatriz Resende, com apoio da Fundação de Amparo à Pesquisa do Estado do Rio de Janeiro - FAPERJ.

2 Professora de Direçáo Teatral do Curso de Teatro do Departamento de Letras, Artes e Cultura da Universidade Federal de São Joáo del Rei. Doutora em Artes Cênicas pela Universidade Federal de São João del Rei. 
e relacionados a pessoas comuns possam ser compreendidos como tragédia, contrariando a afirmativa de impossibilidade da tragédia, e/ou da experiência trágica, na modernidade/contemporaneidade?

A análise de Barafonda como uma tragédia aponta tanto para preceitos conceituais, como o de tragédia moderna em Raymond Williams (2002), quanto para os elementos temáticos da condição do homem comum na cidade contemporânea. Nesse sentido, seguimos o pressuposto de que Barafonda apresenta-se como uma obra cujo conteúdo relaciona-se dialeticamente com a história, ou seja, seguindo a premissa adorniana, incorporada por Peter Szondi para pensar o "Drama Moderno", de que a forma estética é conteúdo histórico precipitado.

Aqui a concepção dialética de Hegel da relação formaconteúdo rendeu frutos, ao se compreender a forma como conteúdo "precipitado". A metáfora expressa ao mesmo tempo o caráter sólido e duradouro da forma e sua origem no conteúdo, ou seja, suas propriedades significativas. Uma semântica da forma pôde desenvolver-se por essa via, e a dialética de forma e conteúdo aparece agora como dialética entre o enunciado da forma e o enunciado do conteúdo. Desse modo, no entanto, é colocada já a possibilidade de que o enunciado do conteúdo entre em contradiçáo com o da forma. Se, no caso da correspondência entre forma e conteúdo, a temática vinculada ao conteúdo opera, por assim dizer, no quadro do enunciado formal como uma problemática no interior de algo náo problemático, surge a contradiçáo quando o enunciado formal, estabelecido e não questionado, é posto em questáo pelo conteúdo. Mas essa antinomia interna é a que permite problematizar historicamente uma forma poética, e o que aqui se apresenta é a tentativa de explicar as diversas formas da dramática moderna a partir da resoluçáo dessas contradiçóes. (SZONDI, 2001, p. 25-26)

O conceito de tragédia operado por Raymond Williams fundamenta-se na articulação conceitual empreendida em Tragédia Moderna (2002). Em sua obra, o autor nos mostra como a tradição não significa uma transposição da verdade diretamente do passado, mas uma interpretação dele, ou seja, a tradição herdada do passado 
pode (e deve) ser compreendida como um constructo de leituras da cultura grega que agregam ou descartam conceitos de acordo com interesses de cada época. Dessa maneira, a tragédia moderna de Williams opóe-se a alguns pressupostos preconizados pela tradição (nomeada como tragédia clássica ou aristotélica), dentre os quais podemos destacar a teoria defendida por Diderot em seu Discurso sobre a poesia dramática (1997), onde propóe um "sistema mais formal de gêneros" definindo a tragédia tradicional "cujo objeto são as catástrofes públicas e os infortúnios dos grandes" (DIDEROT apud CARLSON, 1997, p.149).

Portanto, torna-se importante destacarmos que a tragédia presente na obra Barafonda é aquela cujos personagens não são os de classe social elevada - como príncipes ou aristocratas - mas o homem comum - no caso os trabalhadores, moradores e frequentadores daquele bairro - não apenas retratado em seu cotidiano, no sentido de dramatizar uma história em um palco, mas vivenciado na experiência de percorrer o Bairro tanto geograficamente - no deslocamento de quase dois quilômetros proposto pela encenação - quanto por seu resgate à história e memória local. ${ }^{4}$

\section{AS TRAGÉDIAS CLÁSSICAS}

Como já apontado, o espetáculo estrutura-se a partir de duas tragédias clássicas: Prometeu Acorrentado, de Ésquilo e As Bacantes, de Eurípedes. Tais obras são referidas durante o espetáculo, porém este não se configura como a encenação das tragédias, sendo que as referências a tais obras são colocadas paralela ou perpendicularmente a outras narrativas que dizem respeito ao passado e ao presente do Bairro Barra Funda. Dessa maneira, a dramaturgia é construída como uma trama de situaçóes perpassadas pelas tragédias clássicas e pelo contexto histórico local.

O pesquisador Gilson Motta, na obra $O$ espaço da tragédia (2011), propõe um estudo das encenaçóes de tragédias no Brasil a 
partir dos anos de 1990, mostrando como a mudança no quadro cultural e político na segunda parte do século XX ofereceu um celeiro fértil para as novas perspectivas e experimentaçôes estilísticas a partir da releitura de tragédias clássicas. Motta (2006) aponta, com base na autora Helene Foley, que houve, a partir dos anos 1990, uma grande quantidade de montagens de tragédias gregas. Esse fenômeno, que trouxe impacto para a cena contemporânea, é ressaltado pela autora por alguns motivos que foram considerados na pesquisa de Gilson Motta, dentre os quais elegemos o seguinte para a análise de Barafonda:

A tragédia possibilita a construção de um discurso político não localizado em relação às questôes não resolvidas e às situaçôes extremas. Quando encenada num passado imaginário que oferece poucas possibilidades de descrição física, a tragédia estabelece uma dissolução das referências acerca da jurisdição, dos elementos éticos, raciais e culturais, possibilitando uma resposta política às questóes não resolvidas e às situações extremas, sem localizar nitidamente esta resposta. Textos como Antígona e Prometeu Acorrentado possibilitam, de modo exemplar, a construçáo desse discurso político não tópico. Assim, embora a encenaçáo de um clássico sempre envolve o problema da atualizaçáo e adaptaçáo, ele, por sua própria natureza, se presta a diferentes formas de abordagem e de interpretação, de acordo com os valores contemporâneos. (MOTTA, 2006, p. 106)

A tragédia clássica traz para a encenação a perspectiva de experimentação do ponto de vista estético e estilístico conjugando-a à proposta política da encenação, colocando em questão as diferentes abordagens possíveis do teatro como forma e conteúdo em nossa contemporaneidade.

\section{O CORO OU A CORALIDADE}

O trabalho coral é um dos principais pilares do espetáculo 
Barafonda. Ressaltamos tal presença por dois ângulos, aos quais nomeamos de coro e coralidade. Como Coro, propriamente dito, classificamos toda experimentaçáo cênica baseada na pesquisa e no entendimento do coro grego como forma cênica e dramatúrgica. Como Coralidade, entendemos a conjugaçáo do coletivo como resultado formal.

No primeiro caso, observa-se que a investigação dos modelos gregos trouxe para a estrutura, tanto do texto quanto da cena, experimentos de caráter coletivo, explorando a música e a dança, bem como a composição de quadros cênicos coletivos. A pesquisa de linguagem que deu corpo ao espetáculo caminhou por essa via desde o nome que foi dado a ela: Ao coro retornarás. A atriz Paula Klein aborta essa questão em seu texto publicado no fanzine da companhia, quando menciona sobre o processo de criação:

Buscamos no "coro-entidade" a força ancestral da expressão humana. A instância coletiva do coro como a forma de trazer um outro discurso, que se diferencie da voz individual do artista, geralmente isolada no turbilhão urbano. O coro, representante dos cidadãos do povo, é expressão dessa vocação social do teatro. Um desafio para nós modernos: uma estética coletiva que traduza de fato um pensamento coletivo (CIA. SÃO JORJE DE VARIEDADES, 2010, p. 11).

No caso de Coralidade, ressalta-se a presença do coro no espetáculo através da composição de uma obra que se constrói a partir da escuta e da estruturação de várias vozes coletivas. Tais vozes se fazem presentes seja na construção e elaboração da dramaturgia do espetáculo (resultante de experiência coletiva compartilhada pelos atores), seja na conformação do próprio espetáculo, que consegue dar voz ao coletivo presente no Bairro e, consequentemente, abre ao público a escuta dessa coletividade que o envolve.

Esse fenômeno da Coralidade está presente em diversos trabalhos contemporâneos - como nos mostra Sarrazac em sua obra O Futuro do Drama (2002) - e dialoga diretamente com nosso 
presente histórico, na busca de uma expressão não individualizante que remeta tanto às formas mais democráticas de se encarar a produção artística, no sentido de horizontalizar as relaçóes humanas pelo questionamento das categorias da divisão do trabalho, como também por representar um discurso coletivo que procure olhar para as relaçóes políticas e comuns da experiência contemporânea. A pesquisadora Flora Süssekind nos fala sobre a questão da Coralidade na literatura:

Antes mesmo da eclosão das jornadas de junho, e das manifestaçóes ainda em curso no país, um conjunto significativo de textos parece ter posto em primeiro plano uma série de experiências corais, marcadas por operaçóes de escuta, e pela constituiçáo de uma espécie de câmara de ecos na qual ressoa o rumor (à primeira vista inclassificável, simultâneo) de uma multiplicidade de vozes, elementos não verbais, e de uma sobreposiçáo de registros e de modos expressivos diversos. Coralidades nas quais se observa, igualmente, um tensionamento propositado de gêneros, repertório e categorias basilares à inclusáo textual em terreno reconhecidamente literário, fazendo dessas encruzilhadas meio desfocadas de falas e ruídos uma forma de interrogação simultânea tanto da hora histórica, quanto do campo mesmo da literatura. (SÜSSEKIND, 2013)

As duas categorias - Coro e Coralidade - formam a face de uma mesma moeda, formadoras de um discurso que se pretende opor ao individualizante, buscando formas que deponham como vozes sociais e políticas, reintegrando o homem ao coletivo. Partindo dessa premissa, o trabalho do coletivo em Barafonda experimenta um caminho que tira a ênfase do indivíduo (o herói) e a transfere para o coro, para o coletivo. Raymond Williams, na obra $A$ Tragédia Moderna (2002) enumera alguns fatores que, em princípio entendidos como continuidade da tradição grega, representam uma transformação do conceito original levando-o a uma leitura superficial ou mesmo equivocada da tragédia. $O$ fator que aqui ressaltamos é exatamente a ênfase dada ao herói, ou seja, 
ao indivíduo em detrimento do coro.

As específicas relaçóes entre o coro e os atores formam as suas relaçôes dramáticas reais. A verdadeira ação é a conhecida e atroz história de algumas famílias no poder que tem uma importância geral e representativa na substancia compartilhada do mito. A conhecida história é representada por três atores mascarados, que se separam do coro, mas, como o compartilhar de papéis entre si e a sua relaçáo formal com o coro deixam claro, eles não se separam dele completamente. $\mathrm{O}$ que a forma incorpora, então, não é uma postura metafísica isolada, enraizada na experiência individual, mas uma experiência compartilhada e de fato coletiva - a um só tempo e de maneira indistinguível, metafísica e social. (WILLIAMS, 2002, p. 37)

Essa peculiaridade inerente à tragédia descrita por Williams como "uma experiência compartilhada e de fato coletiva - a um só tempo e de maneira indistinguível, metafísica e social", foi enfraquecida na modernidade no momento em que foi dada ênfase apenas ao herói, eliminando a importância do coro, como aquele que provocava o sentimento e conferia sentido à tragédia. Além de detentor dessa articulação, o coro exerce uma função épica, abrindo perspectivas para a coletividade em cena. "Por sua fala épica e distanciadora ele comenta, generaliza e exprime um phatos que simboliza o próprio phatos dos espectadores" (SARRAZAC, 2012, p. 61).

Houve, em nossa modernidade, um movimento no qual as manifestaçóes coletivas figuradas na presença do coro foram aos poucos sendo substituídas pela experiência individual e particular. Ao primeiro movimento de enfraquecimento do entendimento de tragédia pela ênfase no herói, soma-se o entendimento dessa ênfase como algo inerente ao indivíduo e ao seu livre arbítrio, uma operação plenamente possível quando passa a figurar no palco o burguês, promovendo uma expansão da categoria trágica à nova classe ascendente, como nos indica Rosenfeld: 
Até então, personagens de classe burguesa só podiam aparecer na comédia, assim como as do "povo", na farsa, segundo os cânones tradicionais, o privilégio de ser herói da tragédia era reservado a reis, príncipes, etc. O burguês, como herói trágico, implicava profundas transformaçóes; sua presença impunha mais realismo em menor estilização, o uso de prosa, teor mais profano, náo cabendo a solenidade tradicional, nem a grandeza e a distância místicas. Sobretudo se verificavam a privatizaçáo e particularizaçáo da temática. Esta, tornando-se "doméstica", perdia o caráter público, ligado a heróis cujo destino envolvia o de cidades ou naçóes inteiras. (ROSENFELD, 1993, p. 61)

Para Williams, com a perda da importância do coro e da coletividade, isolamos a experiência e a ideia original de tragédia, sendo-nos legado através da academia um entendimento de tragédia como um tipo específico de arte dramática que, supostamente herdada da tradição grega, se unira à tradição cristã, originando uma experiência Greco-cristá, considerada um dos cernes de nossa cultura ocidental. O autor nos argumenta que a tragédia "não é uma realização estética ou técnica que possa ser isolada: ela está firmemente enraizada numa estrutura de sentimento precisa" (WILLIAMS, 2002, p. 36). Dito isso, podemos levantar o caráter político e social representado pela tragédia, ou seja, uma manifestação cultural que fazia parte da vida na polis, de sua concretude cultural, política e religiosa.

Margot Berthold, na obra História mundial do teatro, fala da realização das Grandes Dionisíacas por parte do estado de Atenas, como ponto "culminante e festivo na vida religiosa", mostrando que o público não era apenas espectador, mas "participava ativamente do ritual teatral, religioso, inseria-se na esfera dos deuses e compartilhava o conhecimento de grandes conexóes mitológicas" (BERTHOLD, 2008, p. 104).

Barafonda busca, através do teatro e do experimento estilístico do coro, uma aproximação com a coletividade do local. Os personagens que vemos durante todo o espetáculo não são apenas indivíduos, mas porta-vozes de um grupo, de uma categoria. Assim, 
os personagens representados no espetáculo aproximam-se muito mais da ideia do corifeu, que se destaca do coro para representálo. Tal proposta cênica proporciona ao espectador sentir-se parte do coro, enquanto que o deslocamento em massa pela cidade propicia um sentimento de coletividade, de um grupo que compartilha uma mesma experiência.

Começamos a nos perceber como coletivos: grupo de artistas, grupo de trabalhadores, de motoristas, de moradores de ruas, de pessoas que correm atrás do tempo ou que preferem perdêlo, enfim, nos é dada a noção de coletividade quando assistimos e somos assistidos. Eis o teatro como evento da cidade, compreendida não apenas em sua estrutura de concreto, mas em sua materialidade humana, propiciando ao espectador uma espécie de conexão (ainda que momentânea) de compartilhamento da experiência coletiva.

\section{A DIALÉTICA DA TRAGÉDIA COTIDIANA}

A ideia desenvolvida pelo coro em Barafonda nos traz o personagem consubstanciado no coletivo, ao qual, dentro dessa premissa, passamos a considerar como personagem principal, protagonista e antagonista da história contada do Bairro Barra Funda, espaço este não apenas compreendido no sentido geográfico, mas em seu capital humano, representado pela figura do homem comum. Nessa perspectiva, as vozes coletivas contidas no passado e no presente do local são expressas e vivenciadas nas figuras dos moradores, artistas, passantes, mostrando como suas histórias são conectadas e comuns.

Ao colocar a coletividade representada na figura do homem comum, trazemos para a leitura trágica de Barafonda, outro ponto desenvolvido por Raymond Williams em sua obra Tragédia Moderna (2002). Refutando o argumento de que não é possível a existência da tragédia no mundo moderno. Opondo-se à visão geralmente veiculada, o autor defende que há experiências em nosso cotidiano 
que podem e devem ser consideradas como tragédias, pois assim como cada momento histórico traz um determinado entendimento do termo, nosso mundo contemporâneo também vivencia a cada dia novos problemas, reivindicando novas formas de análise.

Williams inicia a obra criticando o desdém da tradição ao uso cotidiano da palavra, e "que veem como usos imprecisos e vulgares da palavra 'tragédia' na fala comum e nos jornais" (WILLIAMS, 2002, p. 30). Nesse sentido, Raymond Williams nos mostra como este entendimento de tragédia está envolto em uma ideologia que leva a compreensão de acontecimentos que vemos cotidianamente ao nosso lado ou em noticiários como acidentes, ou seja, meros sofrimentos. "A verdadeira chave para a moderna separação entre tragédia e o 'mero sofrimento' é o ato de separar o controle ético e, mais criticamente, a ação humana, da nossa compreensão da vida política" (WILLIAMS, 2002: 73). Portanto, a distinção entre acidente e tragédia está subjugada a camadas que definem se tal acontecimento é significativo ou não, sendo que uma destas se agrupa exatamente à ideia de que as tragédias estão ligadas à posição social, criando uma linha divisória entre a importância daquilo que aconteça a um homem de posição ou a um escravo, por exemplo.

Ironicamente, a nossa própria cultura burguesa começou por, aparentemente rejeitar essa visão: a tragédia de um cidadão poderia ser táo real quanto a tragédia de um príncipe. Frequentemente, na verdade, essa era menos uma rejeição da estrutura de sentimento, e mais a extensão da categoria trágica a uma nova classe ascendente. E, no entanto, a sua consequência final foi profunda. Assim como em outras revoluçóes burguesas - quando se estendem as categorias de lei ou de eleiçáo - os argumentos para essa extensáo limitada tornam-se inevitavelmente argumentos para uma ampliação geral. A extensão do príncipe ao cidadão tornou-se na prática uma extensão a todos os seres humanos. No entanto, a natureza dessa ampliaçáo determinou em larga escala o seu conteúdo até que se atingiu o ponto em que a experiência trágica foi teoricamente concedida a todos os homens, mas a sua natureza foi drasticamente limitada. (WILLIAMS, 2002, p. 74) 
A ênfase na posição social ligava esse homem diretamente a uma coletividade por ele governada ou incorporada. A sociedade moderna passou, então, a negar a vinculação desse homem de posição ao estado, sendo que na sociedade burguesa ele passa a ser uma "entidade em si mesma", havendo, por um lado, o ganho no sentido da extensão feita do trágico ao homem comum, por outro, a perda do caráter público e político desta extensão que se perdem na ênfase individual dada ao seu destino. A consequência mais séria dessa desvinculação do homem ao Estado, ao coletivo, foi a desvinculação da experiência vivenciada do mundo para "uma ordem puramente abstrata" (WILLIAMS, 2002, p. 74).

Segundo Williams, através da observação da experiência trágica, é possível compreender o "contorno e a conformação de uma cultura específica". (WILLIAMS, 2002, p. 69) Contudo, refutando a tradição analítica da tragédia, o autor coloca a importância de se interpretar a experiência trágica "na sua relação com as convenções e instituições em processo de transformação" (WILLIAMS, 2002, p. 70). Por conseguinte, é necessário romper com a teoria e valorizar a arte, desvinculando-a de sua estrutura de sentimento dominante para dar luz às variações dramáticas atuais, a fim de atuar criticamente de uma forma mais ampla.

$\mathrm{Na}$ tessitura de Barafonda podemos localizar o protagonista, o herói trágico, como o Bairro Barra Funda, representado em sua potencialidade humana na figura do homem comum. Este homem está sujeito às relações estruturadas pelo interesse econômico, que podem ser vistas como sua redenção e seu aniquilamento, mostrando o sistema perverso a que o sujeito está envolto na cidade de São Paulo, como um microcosmo de uma estrutura maior: a estrutura capitalista.

E, como breve conclusão teórica para início de alguns pincelamentos de análise, trazemos a reflexão de Iná Camargo Costa no prefácio de Drama em Cena (2002), acerca do tema, que ressalta como um dos principais aspectos da tragédia de nosso tempo reside, conforme reconhece Williams, no fato de que "as principais 
organizações que no século XX se apresentaram para o combate ao capitalismo em direção ao socialismo passaram a fazer parte do complexo de forças de sustentação da sociedade capitalista" (WILLIAMS, 2002, p. 12), mostrando-nos a desordem das ideias e ações humanas que levam à dialética da tragédia cotidiana, que rapidamente procuraremos detectar no espetáculo como elemento fundamental.

O desenho trágico da narrativa que propõe Barafonda inicia-se no prólogo (elemento estrutural da tragédia clássica). O personagem Raphael Galvez (1907-1998), um artista plástico que morou e manteve seu ateliê na Barra Funda, anuncia em sua primeira fala: "Aqui acaba a história contada por mim. Estamos assistindo à última cena. [...]" anuncia o tempo presente, quando já morto, com 105 anos, começando a conduzir uma viagem rumo ao passado que terminará em sua infância, numa festa no Largo da Banana, optando por um jogo no qual a peça é narrada cronologicamente do fim para o início, do presente para o passado.

Quando Raphael Galvez se apresenta com 105 anos, escancara uma relação entre a vida vivida, a memória e a história. A proximidade da morte dá ao personagem uma visão da vida em perspectiva, questionando o seu valor, a mercantilização do sujeito; e se vê como os jovens, sonhador, ao propor "resgatar o homem e sua unidade perdida". Além da temporalidade, vemos um comprometimento do artista com a sociedade, a obra deve ser terminada para os jovens sem esperanças, como a esperança pudesse ser dada pela arte, mostrando o teor de uma arte comprometida com a sociedade, uma arte que se propõe política. Há também nas palavras de Galvez um determinismo quanto à tragédia que se desenha no cenário do espetáculo: "Estou no fim da nossa linha do tempo e não há mais nenhum passo a ser dado. A obra está pronta. O que faço agora? Caramba, só me resta morrer!"

Um segundo elemento formal/estruturante da tragédia Barafonda (e sua tragicidade), como já dito, é sua organização em coros. Do prólogo, passamos a uma banda de rock que já dá no 
início o tom coral. Também a rádio cipó, funcionando ao longo do espetáculo como um narrador condutor do mesmo, organiza esta percepção. Com o anúncio da rádio, que vai contar a história do Bairro, começamos nossa caminhada. Durante o primeiro percurso, saindo da Praça Marechal Deodoro e seguindo ao longo e abaixo do Viaduto Presidente Arthur da Costa e Silva, os atores compõem quadros na malha urbana. São dezenas de imagens instaladas nas praças, estabelecimentos, ao lado de transeuntes, moradores de rua. Esses quadros direcionam o olhar do público para a cidade, mostrando suas contradições, porém sem trazer à leitura um significado direto e único, mas acionando domínios do sensitivo e do afetivo daqueles que assistem. Portanto, esses quadros colocamse ao lado do real, brincando com ele e, com esse jogo, inventam uma nova realidade, revelando a dialética entre o real e aquilo que poderia ser o real.

Esse mecanismo, como nos lembra Dort, segue o direcionamento e o entendimento de Brecht, no sentido de situar o palco e plateia na história, sendo ela a responsável pela última palavra na organização de uma nova dialética entre o palco, a plateia e a história (DORT, 1980). Os quadros formados pelos atores remetem ao lirismo, quando, por exemplo, dançam na saída de ar do metrô e um longo T.N.T. branco esvoaça numa dança leve. Em sua grande maioria, contudo, os quadros nos parecem imagens críticas, que se referem ao homem diante da cidade, de sua estrutura do consumo e de suas relações humanas desgastadas. Os atores que trabalham os quadros neste primeiro momento do percurso se dividem em três núcleos, ou quatro coros que, num exercício de análise, nomeio cada qual segundo minhas impressões: 1) o primeiro, identificado com macacões de operários cinza é o Coro dos Homens-Cidade. Além da ligação ao homem simples, personagem ou coro principal da obra, vimos, nessa indumentária, uma forte referência ao agit-prop; 2) o segundo, formado por três atrizes, é o Coro das Cabritas (as mesmas que dançam na saída de ar da Praça Marechal Deodoro), elas vestem camisolões brancos e em determinados momentos passam no contra fluxo do cortejo chamando por Prometeu; mais tarde veremos 
que esse coro representa a personagem Io da tragédia Prometeu Acorrentado; 3) o terceiro é o Coro Dionisíaco e é representado pelas figuras da Terra-Mãe - nome dado pelo espetáculo à personagem que chama atenção batendo e gritando com uma enxada contra o asfalto ao longo do percurso de Dionísio, que baila entre os passantes e moradores de rua, e uma figura incógnita, que carrega o número 13 e um longo cajado, sempre por perto, como se tudo observasse, e que ao final do espetáculo descobrimos que tratase do Tangolomango; 4) e o núcleo que forma o carro de som, o Coro Rádio Cipó, que parece representar o momento histórico da formação do Bairro, com indumentárias que remetem ao início do século XX.

Além desses quatro coros (Homens-Cidade, Cabritas, Dionisíaco e Rádio Cipó), também identificamos o público com o comportamento de coro, é o Coro de Espectadores, que se divide em vários: aqueles que estão lá para acompanhar a peça até o final, aqueles que desistem durante o caminho, aqueles que no meio do percurso se interessam e começam a seguir, aqueles que assistem de seu trabalho, de sua janela, enfim, um coro que se divide em infinitas possibilidades.

Com a formação dos coros, descrita suscintamente acima, destaca-se a figura de um corifeu, que terá como papel dar voz ao trabalho/trabalhador. Durante todo o segundo percurso até a chegada à sede do grupo, o trabalho e a condição do trabalhador (e aqui incluímos o artista) é discutida. Numa serralheria instalada em um sobrado, uma cena desenrola-se lembrando-nos de que, como aquela casa, outros pequenos estabelecimentos de serviços acoplados a residências eram comuns em outros tempos e fazem parte na história do local.

A fala do trabalhador corifeu, aliada à memória espacial que acontece na serralheria, traz a reflexão de uma condição há muito estabelecida; passa pela reflexão marxista do trabalho alienado, e das condições para as quais o capitalismo "empurrou" uma grande legião de trabalhadores. 
Quando o trabalhador, ao invés de agradecer a Deus agradece a Zeus, ou fala em matar animais mitológicos a cada dia, nos traz a tragicidade de sua condição, disparando a dialética do trágico e a dimensão política na compreensão da tragédia no cotidiano do homem comum que (para além da reivindicação de Williams (2010) quanto à possibilidade de se considerar o homem comum como herói trágico) nos coloca a contradição (trágica) da situação do trabalhador, segundo a qual o trabalho (sua presença ou sua ausência) é sua redenção, e o caminho para a redenção é o que o leva à ruína:

Pois não é o aniquilamento que é trágico, mas o fato de a salvação tornar-se aniquilamento; não é no declínio do herói que se cumpre a tragicidade, mas o fato de o homem sucumbir no caminho que tomou justamente para fugir da ruína. (SZONDI, 2004, p. 89)

$\mathrm{Na}$ fala do trabalhador, o trabalho é comparado ao castigo, mas ressalta sua contradição na suposição do contrário: "mas castigo mesmo deve ser ficar sem trabalho. Sem propósito, sem serventia, sem utilidade, sem ter porquê, sem ter pra quê”. Nesse ponto percebemos, não apenas a dialética da situação na relação homem-trabalho, mas também a possibilidade de crítica à ideologia que cerca e resguarda o lugar do trabalho na sociedade. Neste contexto, desenha-se a situação trágica contemporânea, em diálogo com a estrutura trágica clássica, não em oposição, impossibilidade. E desta forma, o espetáculo segue conduzido pelas tragédias clássicas e seus mitos (Prometeu, Dionísio, Io, As Bacantes, etc.), a passear pelo lamento trágico do homem comum moderno em sua cidade monstro. De forma sucinta, como é possível aqui, saltamos ao fim do espetáculo, passado, início da história.

Galvez - Aqui começa a história contada por mim, Barafonda, aqui estou eu estatelado no início da linha do tempo que nos consumirá, mas hoje aos 19 , a esperança me toca, tenho sonhos. Barra Funda, quero beber seu passado, pintar seu presente até entender que o cinza 
também é cor e dormir quem sabe no futuro em seu sol quente de fartura. Né. Sonhemos, tenho só 19 anos. Né. Sonhemos, temos só 19 anos. Meus personagens, minhas pinturas, vamos caminhar, estamos só no início, vamos em busca da nossa utopia representada e descobrir que o teatro, a arte, tem o tempo do amor. Vitta nova!

As luzes se acendem e começa a cantoria, a primeira música tocada é uma tiririca, todos dançam e se divertem ao redor da fogueira. Toca um samba que fala do Largo da Banana e, em meio à cena, aparece um policial anunciando que a cadeia está suja e alguém terá que limpar. Ele prende seu Dionísio que, preso, canta o que parece um ponto de jongo: "é fogo no moinho, quem fica no caminho vira toco...”. Anunciam que a prisão é apenas brincadeira e pedem uma moeda para soltá-lo. Depois de solto, pela primeira vez, veremos a fala do personagem Tangolomango:

Tangolomango interrompe: Machado - e diz ao guarda: com a vossa permissáo, faço aqui minha contribuição. Comigo não tem troco. Teje solto seu Dionísio.

Meu nome é Tangolomango. Eram três irmãs numa casa, uma foi dar uma volta na rua, deu o tangolomango nela e ficaram apenas duas. Dessas duas uma viajou pra Paraibuna deu o Tangolomango nela e ficou somente uma. Essa uma, quis comer feijão, deu o Tangolomango nela e acabou-se a geraçáo. Chegou a hora do sorteio do cabrito, minha gente. $\mathrm{O}$ mesmo cabrito que você comeu no futuro, e que no presente viu ser muito bem temperado. Pois esse mesmo cabrito aqui mesmo vai ser sacrificado. Pois assim memo é, comigo não tem coré.

Sua fala nos remete ao churrasquinho que foi oferecido ao público na Praça Marechal Deodoro (início do espetáculo e fim da narrativa) e temperado na sede do grupo (no meio). O nome dado ao personagem Tangolomango é o nome de uma brincadeira folclórica em que alguém, por má sorte, é assaltado pela morte. É feito um jogo de roleta para sortear-se um cabrito, e sai o número 7, número das cabritas Ios, que se recusam a morrer e, ao lutarem pela vida, acidentalmente matam um de seus irmãos. A Terra-Mãe, 
em um ato de desespero, pede a elas que fujam. Na cena, se instaura um profundo sentido trágico unindo vida e morte, como no mito de Dionísio, que em forma de bode é sacrificado e volta a renascer. Passamos a saber agora, ao final, que é também o início, que Io lutava contra um suplício que lhe foi dado não gratuitamente, como nos é dado conhecer na tragédia Prometeu Acorrentado, mas por não aceitar sua sorte, ou seja, sua condição, seu "destino".

O "trágico" que se apresenta no espetáculo, argumenta contra o determinismo, buscando a utopia e o questionamento do status quo, junto à busca de uma história do solo em que se pisa o caminho, vindo do passado, para se vislumbrar o presente e o futuro. O "trágico" que permeia Barafonda é o de homens comuns, trabalhadores, escravos, imigrantes, etc. parte do passado e presente do bairro Barra Funda; parte da vida dos homens comuns, que no mundo capitalista em que vivemos, só pode ser trágica, e por ser trágica, necessita tanta luta. E terminamos com as palavras proferidas por Raphael Galvez, ao final do espetáculo:

Galvez- Quem for apreciar essa minha história, essa minha Barafonda, poderá começar pelo princípio ou pelo fim. Passado, presente, futuro. Estamos no início, mas é o fim. É o Fim? O que esperar do amanhâ?

$\mathrm{O}$ que podemos construir?

Essa história de minha vida não tem começo e nem tem fim, ela começa por acaso e não tem fim, porque depois de eu morto a minha história continua, a nossa história continua, pois ela está ligada a tudo e a todos.

Aqui acaba, quer dizer... aqui começa, a história contada por mim, história verdadeira que expressa uma parte dos fatos que passei relacionados com as pessoas e as coisas do meu tempo.

Os que ficam vão dizer - O Raphael era assim! A Barra Funda não era assim!

Muitos se lembrarão de nós, outros não, mas de fato ficará de mim algo que lembrará - uma cabeça de gesso, uma figura de bronze, um quadro, um desenho, uma peça de teatro, alguns escritos, e principalmente o contato que eu tive com o mundo onde vivi. Cada minuto que passa é uma esperança a menos e é por isso que devemos lutar até o fim. 


\section{REFERÊNCIAS BIBLIOGRÁFICAS}

BERTHOLD, Margot. História Mundial do Teatro. $4^{a}$ ed. São Paulo: Perspectiva, 2008.

CARLSON, Marvin. Teorias do Teatro: estudo histórico-crítico dos gregos à atualidade. São Paulo: Editora Fundação da UNESP, 1997.

CIA SÃO JORGE DE VARIEDADES. Fanzine da Companhia Sáo Jorge de Variedades, n.8, 2010. Disponível em: http://issuu.com/ ciasaojorge/docs/fanzine8/1 ?e=0 . Acesso em: 25 out. 2012.

COSTA, Iná Camargo. "Prefácio". In WILLIAMS, Raymond. A tragédia moderna. São Paulo: Cosac \& Naify, 2002.

MOT'TA, Gilson. O espaço da tragédia: na cenografia brasileira contemporânea. São Paulo: Perspectiva, 2011.

. "A encenação da tragédia grega e o trágico na cena brasileira contemporânea". In: Artefilisofia, Ouro Preto n.1, p. 105-119. Julho 2006.

ROSENFELD, Anatol. Prismas do teatro. São Paulo: Edusp: Perspectiva, 1993.

SARRAZAC, Jean-Pierre. O futuro do drama: escritas dramáticas contemporâneas. Porto: Campo das Letras, 2002.

SÜSSEKIND, Flora. Objetos, 2013. Disponível em: http://oglobo. globo.com/blogs/prosa/posts/2013/09/21/objetos-verbais-naoidentificados-um-ensaio-de-flora-sussekind-510390.asp . Acesso em: 12 dez. 2013.

O léxico do drama moderno e contemporâneo. São Paulo: Cosac Naify 2012.

WILLIAMS, Raymond. Drama em Cena. São Paulo: Cosac \& Naify, 2010. 
A tragédia moderna. São Paulo: Cosac \& Naify, 2002.

\begin{abstract}
The purpose of the present paper is to point out, through the analysis of the dramaturgical structure found in the theater play Barafonda - created by the group from São Paulo/Brazil Companhia São Jorge de Variedades and performed in 2012 - the political aspects enclosed in the esthetic and thematic choices, using the concept of the Modern Tragedy from Raymond Williams.
\end{abstract}

Keywords: Modern Tragedy, Chorality, Theater and Politics. 